\title{
FOUCAULT, TREINTA AÑOS DESPUÉS. A PROPÓSITO DE EL PODER PSIQUIÁTRICO*
}

\section{Rafael Huertas}

Instituto de Historia. CSIC

FouCAULT, Michel. El poder psiquiátrico, Madrid, Akal, 2005. 381 pp.

Foucault, no creo que quepa ninguna duda, es un clásico de las ciencias humanas del siglo XX. Se puede ser o no ser foucaultiano, se puede ser antifoucaultiano, pero su obra no puede dejar indiferente a los que, desde ámbitos de especialización diversos (historia, sociología, filosofía, psiquiatría, psicología, pedagogía, derecho penal, etc.) se han visto abocados a estudiar una parte o la totalidad de sus aportaciones. Dichas contribuciones, además de citadas con profusión, han sido analizadas y discutidas desde hace años tanto en Europa como en América, desde donde parecen regresar con fuerza al viejo continente «redimensionadas» de tal modo que Foucault se nos presenta ahora como el autor más destacado de la llamada French Theory, por delante de Derrida, Lacan o Deleuze. ${ }^{1}$

En más de una ocasión he insistido en que en historia de la psiquiatría, e independientemente del acuerdo o desacuerdo que susciten sus argumentos, no puede negarse que hay un antes y un después de Foucault y que resulta imposible una reflexión historiografía seria de la locura o de la psiquiatría en la que no se le tome en consideración. Por eso, la publicación del conjunto de lecciones que sobre El poder psiquiátrico dictó Foucault en el Collège de France durante el curso 1973-74, pueden suscitar en el lector un doble sentimiento: por un lado, una especie de dejà $v u$, pues en dicho curso se repiten, matizados, muchos de los postulados y razonamientos ya conocidos de Foucault; pero, por otro lado, un reencuentro - también matizado - con este clásico de la teoría sociológica contemporánea, que nos ofrece la posibilidad, y el placer, de leer un texto - cuyos contenidos, conviene no olvidarlo, fueron formulados hace más de treinta años- desde una perspectiva diferente a la que se adopta ante una «novedad bibliográfica», desde el regusto que promete el «inédito» de un clásico.

Como se sabe, desde hace algunos años, Seuil/Gallimard, acometieron la ingente tarea de publicar, bajo la dirección de François Ewald y Alessandro Fontana los cursos que Foucault impartió en el Collège de France. El que nos ocupa, Le pouvoir psychiatrique.

* Proyecto HUM2006-12278-C03-01

1 Véase Cusset, F. (2005), French Theory. Foucault, Derrida, Deleuze y Cia. Y las mutaciones de la vida intelectual en EE.UU. Barcelona, Ed. Melusina. 
Cours au Collège de France, 1973-74, apareció en francés en 2003, y su versión en castellano, con la esmerada traducción de Horacio Pons, ha sido editada por Akal en 2005.

El responsable de la edición de este curso concreto, Jacques Lagrange, lleva a cabo una muy encomiable labor, pues no es solo la cuidadosa trascripción de la voz grabada de Foucault y su comparación con su versión escrita, sino la minuciosa anotación que hace de todo el texto, lo que da al producto final una solidez y un empaque similar a la de otras «entregas» de los cursos.

No se trata aquí, como es lógico, de dar cuenta pormenorizada de los contenidos del libro capítulo a capítulo, pero sí de comentar algunos de los elementos más significativos de estas lecciones y, en particular, los que nos permiten releer y, en la medida de lo posible, «repensar» a Foucault. En este sentido, creo que lo primero que hay que tener en cuenta es que El poder psiquiátrico, aunque podría considerarse una especie de continuación de la Historia de la locura en la época clásica, supone, en realidad, un cambio sustancial con tan emblemática obra. Las «formas de representación» propias de la Historia de la locura dan paso ahora al estudio minucioso del «dispositivo» psiquiátrico; dicho de otro modo, las distintas formas de violencia (prohibiciones, represión, exclusión, coerción, etc.) como expresión de un poder irregular, inmediato e «improductivo», se transforman en una serie de estrategias y maniobras regladas y meditadas que, además, generan o «producen» discursos y saberes que, en definitiva, gestionan un régimen de «verdad».

Este dispositivo psiquiátrico se articula en torno a tres ejes fundamentales, cuya presencia atraviesa constantemente el discurso de Foucault a lo largo de las doce lecciones de su curso: el poder, la verdad y la subjetivación. Estos «puntos de problematización», como los define Lagrange de manera muy breve y aséptica en un interesante epílogo titulado «Situación del curso», me servirán a mí para reseñar las principales características de El poder psiquiátrico.

1) El eje del poder. - Es, naturalmente, uno de los elementos fundamentales de la reflexión de Foucault a lo largo de toda su obra. «El poder no pertenece ni a una persona ni, por demás, a un grupo; solo hay poder porque hay dispersión, relevos, redes, apoyos recíprocos, diferencias de potencial, desfases...» (p. 17). Esta concepción del poder como una red de relaciones en la que todos estamos implicados, devalúa preguntas fundamentales como, por ejemplo: ¿quién posee el poder y con qué derecho?, ¿quién sufre y se beneficia de él?, etc.; interrogantes propios de otros tipos de análisis como, por ejemplo, los de enfoque marxista. En el caso concreto de la práctica asilar, aunque el poder se «individualice», ya que es el psiquiatra el que se instituye como sujeto actuante sobre otros, lo cierto es que el entramado de poder se extiende, en el interior, a través de celadores y asistentes y, en el exterior, mediante otros agentes sociales (jueces, policías, administradores). Pero esta identificación del poder no se hace, en el caso de Foucault, tanto a través de personas o grupos profesionales, sino mediante la caracterización de un dispositivo en el que se aúnan elementos tan heterogéneos como discursos, métodos terapéuticos, medidas administrativas, leyes, disposiciones reglamentarias, ordenamientos arquitectónicos, etc. Un principio de «dispersión» que desagrega saberes y prácticas para poner de manifiesto sus componentes y establecer una «microfísica del poder».

Como es sabido, una de las críticas más habituales a la concepción foucaultiana de poder es precisamente el hecho de que Foucault llama poder a «demasiadas cosas dife- 
rentes», ${ }^{2}$ olvidándose de todo un cuerpo de teoría social, de raigambre weberiana (a pesar de su gran admiración por Max Weber), que se afana en distinguir cuidadosamente nociones como autoridad, fuerza, violencia, dominación o legitimación; de esta forma, se pierde una gama muy amplia de matices normativos. En el caso de la psiquiatría y de la práctica manicomial estas ausencias me parecen especialmente relevantes porque denotan las dificultades del enfoque foucaultiano para averiguar el papel y las razones por las que actúan los distintos agentes sociales que participan en la organización de la asistencia psiquiátrica. Un ejemplo suficientemente significativo es el que tiene que ver con las relaciones entre crimen y locura. Foucault nos lo presenta como una novedad: «un proceso que hasta hoy pasé por alto es el problema de la relación entre la locura y el crimen» (p. 256). Afirmación hecha en la clase del 23 de enero de 1974, a los pocos meses de haber publicado el Moi, Pierre Rivière...y en pleno proceso de preparación de Vigilar y castigar. Para Foucault, las relaciones entre crimen y locura desempeñaron un importante papel en la elaboración de nociones como peligrosidad social, ya que no se trataba solo de dilucidar si determinados actos criminales podían haber sido realizados por un individuo con la mente trastornada, sino, invirtiendo el razonamiento, si cualquier loco podría llegar a cometer un crimen. Las relaciones entre crimen y locura aparecen así, según Foucault, como uno de los fundamentos del poder psiquiátrico, no tanto en términos de verdad, sino en términos de defensa social. El planteamiento es, sin duda, importante y abrió una vía de investigación y de reflexión que ha dado grandes frutos, pero cabría preguntarse si cuando se habla de poder psiquiátrico en el asilo y de poder psiquiátrico en los tribunales de justicia estamos hablando realmente de lo mismo. El escenario es diferente, así como las relaciones - de poder - entre los distintos actores. Para que los jueces tuvieran en cuenta las opiniones de los médicos, para que éstos fueran reconocidos como expertos competentes ante los tribunales fue necesario un proceso de negociación largo y complicado en el que los psiquiatras aspiraban no tanto al «poder», sino al reconocimiento de su autoridad científica y a una mayor legitimación profesional y social. De ahí, que englobar bajo el término «poder», aspectos tan matizables como autoridad o legitimación impiden llevar a cabo análisis más finos del proceso psiquiátrico. Soy consciente de que hablo con ventaja, pues cuento con el bagaje de una serie amplia de trabajos posteriores que han puesto el acento en estas cuestiones, ${ }^{3}$ y precisamente por eso, pienso que no se puede negar la intuición preclara de Foucault al identificar el problema de las relaciones

2 FRASER, N. (1981), «Foucault on Modern Power: Empirical Insights and Normative Confusions», Praxis Internacional, 1, 272-287.

3 Véase, a modo de ejemplo, PESET, J.L. (1996), «Jurist versus doctors: The birth of legal medicine in the United States», History of Psychiatry, 7, 299-317: NYE, R.A. (1984), Crime, Madness and Politics in Modern France. The Medical Concept of National Decline, Princeton, Princeton University Press; HARRIS, R. (1989), Murders and Madness. Medecine, Law and Society in the 'fin de siècle', N. York, Oxford University Press.; RenNEviLle, M. (1996), La médecine du crime. Essai sur d'émergence d'un regard médical sur la criminalité en France (1785-1885), París, Septemtrion; HuerTAS, R. (2002), Organizar y persuadir. Estrategias profesionales y retóricas de legitimación de la medicina mental española (18571936), Madrid, Frenia.(en especial pp. 127 y ss) 
entre crimen y locura como uno de los aspectos cruciales de la historia de la psiquiatría. Tampoco debemos olvidar que el propio Foucault, años más tarde, reformuló en cierto modo sus ideas al distinguir entre «las relaciones de poder como juegos estratégicos de libertades», en los que «algunas personas intentan determinar las conductas de otras», de las «situaciones de dominación (...) que normalmente llamamos poder». ${ }^{4}$ La idea de una sociedad sin relaciones de poder resultaría un sinsentido, mientras que la reducción de situaciones de dominación a un mínimo debe ser un objetivo político prioritario. Pero esta reflexión es muy posterior a sus lecciones de los años setenta en las que el «poder» sigue apareciendo de manera omnímoda y sin aparentes fisuras en sus razonamientos.

En El poder psiquiátrico, Foucault se esfuerza en explicar, una vez más, las diferencias entre el «poder de soberanía» y el «poder disciplinario»y, de manera particular, el paso de la violencia a la microfísica del poder. Según Foucault, lo que caracteriza al régimen de disciplina moderno es la manera en que la coacción mediante violencia ha sido sustituida, en gran medida, por el más amable cuerpo de la administración, por expertos científicamente preparados $y$, en definitiva, por la exhibición pública de poder mediante el despliegue imperceptible de técnicas basadas en un conocimiento detallado de sus objetivos. La relación saber-poder desempeñaría, en este sentido, un papel fundamental en todo este proceso.

2) EI eje de la verdad. - En tanto que el alienado queda constituido como objeto de saber, el asilo, en tanto que dispositivo disciplinario, es también el lugar de formación de un cierto tipo de «verdad». La construcción de nosologías y clasificaciones psiquiátricas, la cuestión del diagnóstico, la «prueba de realidad» y sus formas: el interrogatorio, el ritual de la presentación clínica, las modalidades terapéuticas, etc., aparecen aquí como un producto directo del sistema disciplinario. La verdad se produciría, según Foucault, gracias a múltiples coacciones, siendo un producto de la aplicación «racional» de normas, prescripciones, procedimientos, etc. La irracionalidad, la incompetencia, la desviación, el error, el sinsentido (lo «otro de la razón» en suma) quedan definidos por sus contrarios y, sobre estas bases, las personas y las prácticas son valoradas o estigmatizadas, premiadas o castigadas, rechazadas o revestidas de autoridad (o de «poder» en el amplio sentido foucaultiano). Pero resulta interesante, y por demás significativo, cuando ese principio de verdad deja de relacionarse con el enfrentamiento entre la «razón» y la «sinrazón», entre el médico y el «enfermo», para pasar a plantearse exclusivamente dentro de un poder psiquiátrico establecido e identificado con la ciencia médica. El concurso de la anatomía patológica en este proceso resulta crucial.

Como ya demostrara en El nacimiento de la clínica, Foucault conoce bien el tema y lo utiliza ahora para explicar de qué manera, al convertirse la autopsia en la clave del diagnóstico, la palabra del loco o la «crisis», como el momento de la verdad de la locura, quedaba relegada en favor de los hallazgos necrópticos. No importaba lo que el loco pudiera decir o hacer, pues el análisis de su cuerpo - tras su muerte - ofrecería la verdad sobre su locura. Ya sabemos, y Foucault también lo sabía, que salvo en la Parálisis Gene-

4 La cita corresponde a una entrevista concedida por Foucault en 1984 y publicada como «The Ethic of the Care for the Self as a Practice of Freedom». En BERNAUER, J. y RASSMUSSEN (ed.), The Final Foucault, Cambridge, MA, pp. 1-20; p. 19. 
ral Progresiva, las lesiones anatómicas de la locura difícilmente serían demostradas en un estudio post-morten, pero ello no impedía que la anatomía patológica contribuyera a escatimar al loco su palabra y su discurso.

Esta interpretación de Foucault resulta brillante y, aunque está hecha en clave de saber y verdad - esto es, sin salirse del modelo hermenéutico del que él mismo se había dotado-, no cabe duda que introduce elementos de reflexión que pueden relacionarse con otras facetas explicativas, como por ejemplo, la importancia de la llamada mentalidad anatomoclínica, no solo en la elaboración de una semiología psiquiátrica próxima a la de la medicina interna 5 , sino en el proceso de somatización de la locura a lo largo de todo el siglo XIX; un proceso en el que las ideas trastornadas o las pasiones desbordadas dejaron de ser «enfermedades del alma» para considerarse la consecuencia de lesiones anatómicas concretas ${ }^{6}$. Esta somatización, o biologización, de la locura dio lugar a consecuencias muy relevantes en el ámbito clínico, tanto en el terapéutico (el abandono del tratamiento moral), como en el diagnóstico y evolutivo, con la consideración de la degeneración, la demencia y el delirio crónico como la triada definitoria de la cronicidad de la enfermedad mental ${ }^{7}$.

Sea cual sea el acercamiento historiográfico que consideremos, lo cierto es que la reflexión de Foucault es crucial. El loco queda desprovisto de la palabra, no es digno de ser escuchado. La clínica de la mirada (de la observación «objetiva» del experto) será la característica del saber psiquiátrico (y del modelo disciplinario impuesto por dicho saber), al menos hasta que el psicoanálisis introduzca novedades importantes aunque parciales en la práctica clínica y, naturalmente, en las relaciones de poder.

Especialmente interesante resulta, en esta «política de verdad» ligada al conocimiento, las páginas dedicadas a la histeria. Con frecuencia se ha afirmado que la historiografía del control social de inspiración foucaultiana no tiene en cuenta las resistencias $-\mathrm{o}$ la capacidad negociadora - de las víctimas; que el «poder» aparece como algo impuesto por las élites científicas o políticas, desplegando sus estrategias y sus efectos sobre una población pasivamente indefensa. Pienso que dicha crítica tiene razón de ser en muchos casos y que son necesarios más trabajos que profundicen en esas resistencias y en la consideración de otros «lugares de enunciación» que no sean los de los expertos «reconoci-

5 Huertas, R. (2005), El siglo de la clínica. Para una teoría de la práctica psiquiátrica. Madrid, Frenia.

6 Véase Scull, A. (ed.) (1981), Madhouses, Mad-doctors and Madmen. The History of Psychiatry in the Victorian Era, Philadelphie, University of Pennsylvania; BYNuM, W.F., PORTER, R. y SHEPHERD, M. (eds.) (1985), The Anatomy of Madness. Essays in the History of Psychiatry, Londres-N. York, Tavistock; JACYMA, J.S. (1982), «Somatic theories of the mind and the interest of medecine in Britain, 1850-1879», Medical History, 26: 233-358. Nuestro propio grupo también reflexionó sobre estas cuestiones en Álvarez, R., HuERTAS, R. y PESET, J.L. (1993), «Enfermedad mental y sociedad en la Europa de la segunda mitad del siglo XIX», Asclepio, 45 (2): 41-60.

7 Sobre estos aspectos ha escrito páginas fundamentales LANTÉRI-LAURA, G. (1972), «Chronicité dans la psychiatrie française moderne», Annales ESC, 27, 548-568.; También LANTÉri-Laura, G. (1997), La chronicité en Psychiatrie, Paris, Syntelabo. 
dos» sino los de los grupos subalternos. Como es sabido, la elaboración gramsciana de subalternidad hace referencia a aquellos grupos que con formas y grados variables negocian el grado de adhesión a los discursos y praxis hegemónicos.

Sin embargo, las páginas de El poder psiquiátrico nos ofrecen una muestra muy interesante de la «resistencia histérica» ante el «poder psiquiátrico». Las histéricas de la Salpètriêre cuestionan el papel del médico — nada menos que del gran Charcot — como el encargado de producir la verdad sobre la enfermedad en el espacio hospitalario. La histérica, seducida por la existencia de los síntomas, los hace suyos, los modifica, los altera; engaña al clínico que se ve obligado a construir forzada y erróneamente, como hizo Charcot, un modelo clínico de «verdad» que fue discutido y desautorizado por sus colegas de la escuela de Nancy en un episodio bien conocido y estudiado por la historiografía $^{8}$. La originalidad de Foucault consiste en contraponer la demencia frente a la histeria. El demente es descrito como el resultado del poder médico y de la disciplina asilar, una disciplina que acaba puliendo los síntomas para construir una locura uniforme y aprehensible. Frente a la demencia, la histeria con su variedad de síntomas y de recursos. "La histeria» - afirma Foucault — «fue la manera concreta de defenderse de la demencia; la única manera de no ser demente en un hospital del siglo XIX consistía en ser histérico, esto es oponer a la presión que aniquilaba y borraba los síntomas, la constitución, la erección visible, plástica, de toda una panoplia de síntomas» (p. 261). Por esta razón, por no aceptar ni la disciplina, ni el poder, ni la verdad, Foucault llega a definir a la histérica como «la primera militante de la antipsiquiatría» (p. 261). Tal afirmación, tan provocadora como exagerada, no deja de tener cierto atractivo a la hora de valorar cómo determinadas parcelas de la práctica médica (o científica) escapan al principio de realidad y de verdad construido por la ciencia. ${ }^{9}$ Atractivo que no invalida el hecho probado de que la histeria siempre bordeó la ortodoxia alienista y que no fueron los psiquiatras de los asilos decimonónicos, sino los médicos generalistas y los neurólogos (como Charcot) los que se ocuparon del estudio y tratamiento de la histeria. Por eso la confrontación entre demencia e histeria resulta equívoca, pues ambas «patologías» pertenecían, al menos en la época a la que nos estamos refiriendo, a jurisdicciones científicas diferentes.

Foucault retomará la cuestión de las «resistencias» años más tarde, en relación con su Historia de la sexualidad, aunque tal concepto queda difuminado en una cierta reivindicación del placer (del cuerpo y sus placeres) que no acaba de establecer, a mi juicio, una categoría de análisis concreta.

3) El eje de la subjetivación/normalización. - El sujeto debe hacer suyas las normas que se le imponen. La disciplina como instancia normalizadora es otro de los argumentos constantes en el discurso de Foucault. Las alusiones al tratamiento moral aparecen en varias de las clases del curso y la obra de François Leuret es analizada desde

8 De obligada referencia, en nuestro medio es la aportación de LÓPEZ PIÑERO, J.M. y Morales Meseguer, J.M. (1970), Neurosis y psicoterapia. Un estudio histórico. Madrid, Espasa-Calpe.

9 Para una historia cultural de la histeria que reflexiona brillantemente sobre la múltiples caras de la misma, como un producto social, véase EDELMAN, N. (2003), Les métamorphoses de l'hysterique. Du debut du XIXe siècle à la Grande Guerre. París, La Découverte. 
varios puntos de vista. No es de extrañar, pues precisamente Du traitement moral (1840) ha sido considerada como la obra en la que más claramente aparecen los desarrollos -y los excesos - de ese modelo pedagógico-disciplinario que dio en llamarse «tratamiento moral», pero también donde más específica y detalladamente aparece la tecnología del mismo: todo un arsenal de aparatos, métodos y técnicas coercitivas destinados a convencer al loco de su «error». Una fuente privilegiada para analizar el funcionamiento concreto de la disciplina asilar, la microfísica del poder psiquiátrico, que es, en definitiva, la máxima aspiración de la propuesta foucaultiana ${ }^{10}$.

La reflexión sobre la norma está presente también en las páginas dedicadas al desplazamiento del poder psiquiátrico hacia el mundo de la infancia. Su maestro Georges Canguilhen en Lo normal y lo patológico, había establecido que «Normal es el término mediante el cual el siglo XIX designará el prototipo escolar y el estado de salud orgánica» ${ }^{11}$, y creo que esta idea es retomada por Foucault cuando define el hospital y la escuela - la institución sanitaria y el método de enseñanza-, como los dos espacios privilegiados de la normalización, a los que poco después, y con los matices necesarios, se añadiría la prisión. Pues bien, en sus disquisiciones sobre la psiquiatrización de la infancia, Foucault aventura que la figura del «niño loco» aparece de manera tardía y plantea la hipótesis de que dicha psiquiatrización del niño pasó no por una relación constitutiva entre locura e infancia, sino a través de un personaje distinto: el niño imbécil o idiota; esto es, el niño retrasado o débil mental. Hoy sabemos que lo que Foucault formulaba - o escenificaba- como una modesta hipótesis, se ha confirmado plenamente: la psiquiatrización de la infancia surge del interés del alienismo por una serie de niños que no están locos, sino que son portadores de una discapacidad, de un handicap, y esto se produce tanto en el plano teórico — no hay más que revisar el concepto de idiocia desde Esquirol a Seguincomo en el práctico y administrativo, con la creación de servicios específicos de niños idiotas y epilépticos en los asilos psiquiátricos franceses. Las psicosis infantiles no se describirán hasta comienzos del siglo $\mathrm{XX}^{12}$.

En definitiva, la más que recomendable lectura de El poder psiquiátrico, nos puede refrescar conceptos y repasar un modelo de análisis revulsivo y provocador, siempre que esa lectura no sea anacrónica o ingenua. Siempre que tengamos presente que se trata de un texto editado en 2003 (2005 en castellano), pero pensado y relatado a comienzos de los años setenta. Solo así podremos valorar en su justa medida, el valor y el interés de una aportación, pienso que crucial, para comprender la evolución del pensamiento de su autor, porque complementa, matiza y enriquece la Histoire de la folie, y también porque se

10 El tratamiento moral $-\mathrm{y}$ su práctica en el espacio manicomial- es, en definitiva, una de las piedras angulares en la que se basó el primer alienismo. También en la década de los setenta, pero desde una perspectiva no foucaultiana, el tema fue abordado por ScULL, A. (1979), «Moral treatment reconsidered: some sociological comments on an episode in the history of British Psychiatry», Psychological Medicine, 9, 421-428

11 Canguilhen, G. [1943] (1972), Le Normal et le Pathologique, París, Presses Universitaires de France, p. 175.

12 Sobre estos temas, puede verse HUERTAS, R. (1998), Clasificar y educar. Historia natural y social de la deficiencia mental, Madrid, CSIC. 
sitúa en un momento clave en la propia historia de la psiquiatría del siglo XX. Por eso me voy a permitir proponer otra lectura posible de El poder psiquiátrico, no tanto como la aportación de un clásico a la historia del pensamiento psiquiátrico, sino como fuente para la historia del movimiento antipsiquiátrico y de las propuestas de impugnación de la psiquiatría y de la asistencia psiquiátrica que tuvieron lugar durante los años sesenta y setenta del siglo XX.

La Histoire de la folie apareció en 1961, de manera prácticamente simultánea con Asylums ${ }^{13}$ de Erving Goffman y con The Mhyte of Mental Illness ${ }^{14}$, de Thomas Szas; pero 1961 es también el año en que Franco Basaglia llegó a Gorizia e inició una de las más emblemáticas experiencias desinstitucionalizadoras. Diez años más tarde, no solo había tenido lugar el mayo francés o la primavera de Praga, también se estaba en condiciones de valorar la existencia de una «psiquiatría diferente», según la expresión de $\mathrm{T}$. Laîné15. La citada experiencia de Gorizia fue explicada con detalle en una obra casi mítica titulada La institución negada (publicada en italiano en 1968 y en francés en 1970). ${ }^{16}$ En Francia, la «revolution post-esquirolienne» propugnada, entre otros, por Lucien Bonnafé17, dio lugar a la llamada «psicoterapia institucional», que tendría como referencia indiscutible, al menos en su primera época, la clínica de La Borde, fundada por Jean Oury y Felix Guattari. ${ }^{18}$ También el exiliado catalán F. Tosquelles aportó en 1971 reflexiones sobre la problemática del poder en la práctica psiquiátrica. ${ }^{19}$ Finalmente, los representantes de la antipsiquiatría británica publicaron sus obras más paradigmáticas a finales de los años sesenta, incluso sus versiones francesas aparecieron justo antes de $1973,{ }^{20}$ año del comienzo del curso de Foucault.

En definitiva, creo que El poder psiquiátrico hay que entenderlo como una contribución consciente al movimiento antipsiquiátrico en una dinámica de investigación/acción.

13 Goffman, E. (1961), Asylums: Essays on the Social Situation of Mental Patients and Other Inmates. N. York, Doubleday (edición francesa: 1968; española: 1984)

14 SzAS, Th. (1961), The Myth of Mental Illness: Foundations of a Theory of Personal Conduct. New York, Paul B. Hoeber.

15 LAINe, T. (1973), «Une Psychiatrie diferente pour la malaise à vivre ». La Nouvelle Critique, abril, pp. 23-36.

16 Basaglia, F. (ed.) (1968), L'Istituzione negata. Rapporto da un ospedale psichiatrico, Turín, Nouvo Politectico.

17 Bonnafe, L. (1960), «De la doctrine post-esquirolienne», L'Information Psychiatrique, 36, 423-444; 559-570.

18 Sobre la experiencia de La Borde, es de gran interés el número especial de Recherches, 21 Histoires de La Borde. Dix ans de psychothérapie institutionelle à la clinique de CourCheverny, suplemento.

19 Tosquelles, F. (1971), «La problématique du pouvoir dans les collectifs de soins psychiatrique », La Nef, 42, 93-101.

20 LaING, R. (1967), The politics of Experience and the Bird of Paradise, Londres, Tavistock (versión francesa, 1969; castellana, 1977); CoOPER, D. (1967), Psychiatry and Antipsychiatry, Londres Tavistock (version francesa 1970; castellana, 1985); COOPER, R. y LAING, D. (1964), Reason and Violence, Londres, Tavistock (versión francesa, 1972; castellana, 1973). 
Foucault toma como punto de partida la situación actual (la de 1973) de la psiquiatría a la luz de las aportaciones de los autores llamados antipsiquiatras o considerados en el ámbito de la antipsiquiatría, para proponer, aplicando el método genealógico, un análisis de las relaciones de poder que condicionaban el funcionamiento de la institución asilar y que dirigían las formas de intervención médica. Como Basaglia, Cooper o Bonnafé, él también intenta impugnar la psiquiatría y negar la institución; de ahí su evolución desde el estudio de la enfermedad mental (la locura) al de la medicina mental (la psiquiatría). Lo hace con las herramientas conceptuales y metodológicas que le son propias, lo cual no es ni una limitación, ni una ventaja, sino simplemente la consecuencia de su formación y de su enorme capacidad de erudición.

En cualquier caso, un lujo y un reto intelectual pues, en esta ocasión, podemos leer a Foucault con la mente abierta, ni como un catecismo para iniciados, ni como un libelo difamatorio. Por el contrario, podemos hacerlo como un clásico, cuya revisión siempre ofrece nuevos motivos de reflexión, o como un autor que, como todos, fue hijo del tiempo concreto que le tocó vivir. 